\title{
Two passions, one goal, and a pandemic: the future of medical education in South Africa
}

\author{
C Quan \\ Department of Anaesthesiology, University of the Witwatersrand, South Africa \\ Corresponding author, email: barrowceleste@gmail.com
}

\section{Summary}

Medical education in South Africa is experiencing two major disruptions: the Fourth Industrial Revolution and the COVID-19 pandemic. I will explore the effects these events have had on our education and possible solutions in the context of our country.

Keywords: medical education, future, Fourth Industrial Revolution, COVID-19 pandemic

\section{Introduction}

In 2011, through sheer good fortune (a combination of living and working abroad, as well as connecting with the right people under conducive circumstances), I managed to obtain a Diploma in Regional Anaesthesia through Montpellier University. I returned to South Africa in 2012 with the specific intention of teaching ultrasound-guided regional anaesthesia (UGRA). I had unique knowledge and skill, but my difficulty transposing it to learners and my frustration with my impatience irked me. I am intrigued that those of us in academic medicine have the enormous responsibility of teaching and training our future anaesthetists, yet the vast majority of us have no training in teaching and learning theories and methods, assessment, and curricula development. I knew for my personal teaching journey, that there was room for massive improvement. As a result, I have enrolled in a Postgraduate Diploma in Health Sciences Education through the University of the Witwatersrand, which I will hopefully complete by the end of 2020. My two passions of regional anaesthesia and education have converged into the one goal of teaching UGRA.

Grant ${ }^{1}$ has said that a curriculum for medical education is an "ideological, social and aspirational statement.... that is fit for the purpose and context of its place and day". The context of the day is especially pertinent as we have had two major disruptions: one being the Fourth Industrial Revolution and the other being the COVID-19 pandemic. I will explore both these disruptions as well as address the issues of the context of South Africa as far as the future of medical education is concerned.

\section{Disruptions}

The word "disruption" has perhaps been overworked and timeworn since it was first used in Clayton Christensen's 1997 book: The Innovators Dilemma".2 The word implies an "interruption" to a process but not a stop. We are living in a time of not one, but two major disruptions: The Fourth Industrial Revolution as well as the COVID-19 pandemic. Disruption would be futile if we emerge on the other side defeated and dejected.
On the other hand, a disruption can shake us out of our comfort zone and push us into chartering new unexplored territories to emerge better and stronger.

\section{The Fourth Industrial Revolution}

Industrial revolutions describe eras of technology which have greatly assisted mankind in making their lives easier on all levels. The First Industrial Revolution started at the end of the 18th century and hailed the advent of steam and mechanisation. A century later, the Second Industrial Revolution arrived with electricity being a new source of energy. The Third Industrial Revolution arrived roughly 100 years later with the advent of electronics and information technology. ${ }^{3}$ The Fourth Industrial Revolution was coined by Klaus Schwab ${ }^{4}$ and consists of a fusion of technologies that consist of physical, digital, and biologic spheres. It includes the fields of artificial intelligence, robotics, the Internet of Things, autonomous vehicles, 3-D printing, nanotechnology, biotechnology, materials science, energy storage, and quantum computing. ${ }^{4}$ These advances are going to lead to medical and technological breakthroughs which will transform health and healthcare. ${ }^{5}$ The important point regarding the Fourth Industrial Revolution in the context of medical education is that the speed of current breakthroughs has no historical precedent and this revolution is evolving at exponential as opposed to linear pace.

The consequence of these rapid impending changes is twofold: our medical curricula and syllabi will have to change accordingly, and we will have to focus more strongly on continuing professional development (CPD). Hamilton ${ }^{6}$ has iterated that outcomes in medical education must be "wide, long and deep". We have to accept that part of our training will become outdated and to stay current we will have to learn new skills, more so than ever before. Doctors have to accept that once the profession of medicine is entered, they need to commit to lifelong learning. For example, our understanding of the basic science of cardiac physiology may not change much over the years, but the measurement of cardiac output may change significantly and require upskilling. 
Standard of care practices may also change significantly over time. For example, prior to 2010, ultrasound machines were not universally available in operating theatres in South Africa. However, now ten years later, it is standard care to insert central lines and perform regional anaesthesia with ultrasound guidance. ${ }^{7,8}$

\section{Teaching and learning in the Fourth Industrial Revolution}

For a successful teaching and learning experience to occur, one requires a motivated learner and a teacher who is well versed with the material. Knowles ${ }^{9}$ has described how adult learners differ from child learners in six respects:

1. The need to know (Why do I need to know this?)

2. The learners'self-concept (I am responsible for my own decisions)

3. The role of the learners' experiences (I have experiences which I value, and you should respect)

4. Readiness to learn (I need to learn because my circumstances are changing)

5. Orientation to learning (learning will help me deal with the situation in which I find myself)

6. Motivation (I learn because I want to)

Learners' motivation is also strongly linked to the frame of mind towards learning and this is also central to the self-determination theory. ${ }^{10}$ Learners also have to realise that the first phase of learning is a dissonance phase when their existing knowledge will be challenged and found to be lacking. The challenge can be internal (within the learner) or external (exerted by a teacher). This phase ends when the learner reflects and determines their personal learning outcomes. In other words, the start of new knowledge integration always begins with feelings of discomfort. This is normal. In summary, adult learners have to have intrinsic motivation, feel that their learning is relevant, and they have to accept and understand that gaining new knowledge is never comfortable nor easy.

Communities of clinical practice (CCoP) have also been recognised as an important aspect of medical education. ${ }^{11}$ Communities of practice have been defined as "groups of people who share a concern or a passion for something they do and learn how to do it better as they interact regularly".12 Learners begin by practicing legitimately on the periphery of particular CCoP. With training, the learners gradually move to the center of the community towards full participation. Newcomers are most likely not competent in the repertoires of the community, but their legitimacy allows their errors to become learning opportunities and their peripherality limits the effects of their mistakes and allows exposure to actual practice but with less intensity. ${ }^{11}$ If we consider anaesthesia as a distinct CCoP, we have to accept that the movement of learners is dynamic within the CCoP: they move to the centre but may also move back to the periphery. In other words, more experienced anaesthetists can be taught new knowledge by "younger" participants.

\section{COVID-19 pandemic}

The unexpected advent of the COVID-19 pandemic has made us all sit up, reset, rethink and reflect on all aspects of our lives personally and professionally. The pandemic has necessitated dramatic restructuring of the workforce, trainees have had to be redeployed, at-risk teachers and learners have had to be shielded from clinical practice and elective procedures have had to be delayed. Social distancing guidelines have precluded having many people in one teaching space as well as in the operating theatres. The scarcity of personal protective equipment has also limited people in a clinical environment. All academic activity (teaching, meetings and assessments) has had to be moved online without much preparation or warning. However, out of adversity comes opportunity. Proposed solutions for these problems include embracing online learning, simulation and "sprint" courses. ${ }^{13}$ In addition, micro-credentialing is another factor to consider.

\section{Online and blended learning}

The advantages of online activities have been a revelation for many. It is independent of geography and traffic. Online activities can be synchronous or asynchronous. Synchronous activities allow for real-time interaction which is extremely advantageous as learning and thinking are social activities. ${ }^{10}$ Asynchronous activity allows learners and teachers to engage at a time that is convenient and flexible. It is also not limited by time zones. Leaner-learner and teacher-learner interaction are possible, but it is not face-to-face and not in real-time. COVID-19 has demonstrated that the time for experiential learning in a work-based environment in South Africa is limited. For example, with regards to UGRA, besides teaching and learning procedures, we still have a clinical job to perform with all the time pressures imposed by the clinical burden and surgical colleagues. In addition, the teacher cannot always dedicate teaching time to one trainee in one operating theatre. Much of the knowledge and skills required for competency can be taught online asynchronously, thereby saving time for pure clinical performance practice. This would be an example of "blended" learning which can be defined as "the thoughtful integration of classroom face-to-face learning experiences with online learning experiences".14 For example, if the objective for a learning exercise was to perform a UGRA block of the brachial plexus with an axillary approach, the learner could be taught the theoretical knowledge required to perform the procedure online asynchronously. This would include, the anatomy of the brachial plexus, pharmacology of local anaesthetic agents and the physics of ultrasound. This allows for scaffolding of knowledge by breaking down a complex skill into achievable learning objectives and hopefully preventing the problem of liminality. ${ }^{10}$ In addition, breaking down the steps utilises the self-regulation theory and will improve motivation and performance by setting process goals as opposed to outcome goals. ${ }^{15}$ Learners can then watch videos of experts performing the block and vocalising the steps in the process. Whilst nothing can substitute handson clinical teaching, the benefit of video teaching is not to be underestimated and is non-inferior to bedside teaching. ${ }^{16}$

\section{Simulation}

Simulation is a method of teaching by producing an experience without going through the real event. It is thus a useful modality 
for times where clinical exposure is limited (for example from lack of elective patients during COVID-19), if the event is rare (for example malignant hypermetabolic syndrome), to prevent unsafe and dangerous situations, to have control over the sequence in which a learner engages with tasks and to be able to offer the learner support and guidance. ${ }^{17}$

\section{Sprint courses}

Sprint courses are immersive, high-volume training that allows rapid progression in technical skills. ${ }^{13}$ For the teaching of UGRA, an example of this would be assigning a trainee with a teacher, and instead of doing a theatre list, they would perform UGRA on any patient requiring the service in the theatre complex.

\section{Micro-credentialling}

Micro-credentials allow individuals to demonstrate competence in a variety of areas and to update existing or obtain new knowledge. In other words, they are "mini-degrees" in a specific, targeted area so they deliver customised learning for specific job-related tasks. Micro-credentials must be validated through a rigorous, standardised and competency-based review. ${ }^{18}$

\section{The context of South Africa}

South Africa is a unique country with very unique challenges. It is plagued by gross inequality, as has been demonstrated by a report released by Statistics South Africa, employing the Gini coefficient and the Palma ratio. ${ }^{19}$ In addition, the economists Erik Brynjolfsson and Andrew McAfee have pointed out that the Fourth Industrial Revolution could result in greater inequality, with unskilled labour losing jobs and skilled labour benefiting the most. ${ }^{4}$ COVID-19 too, has widened the gap between the rich and the poor. Moreover, in a document released by the South African National Department of Health, it has been shown that in 2019, there were 2,03 specialist anaesthesiologists per 100000 population with almost 15 -fold more anaesthesiologists in the private versus the public sector. The recommended number of anaesthesiologists projected to be needed in 2025 is 5,23 per 100000 population. ${ }^{20}$ In other words, in the next five years, our goal is to more than double the number of anaesthesiologists. Education is contextual. We cannot hang on to colonialist thinking and believe that the Western world's approach to medical education is appropriate in our country. Frenk et al. ${ }^{21}$ have outlined a vision for the education of health professionals for the 21 st century in their landmark Lancet report. While our education has to be contextual, we must harness the power of transnational flows of information, knowledge and resources (for example information technology, open education and twinning programmes ${ }^{21}$ ). Wi-Fi is the new currency and the high cost of data in this country must be addressed. Places of learning (including academic hospitals) must look at providing their staff with Wi-Fi access. Online learning in our context is extremely powerful as it is easily scalable and can easily be accessed in remote rural areas. Africa can benefit from twinning programmes that foster exchange, sharing of resources and collaborative work for mutual advance.

\section{Conclusion}

As a profession and as far as the training of our profession is concerned, we no doubt, have massive challenges ahead of us. Reform is required and this begins with a change in mindset that accepts the challenges and seeks to resolve them. Education reform is long and difficult and will require leadership, changing perspectives, work styles and involvement of all stakeholders (professional bodies, universities, non-governmental organisations, international agencies and foundations).

\section{Conflict of interest}

The author declares no conflict of interest.

\section{ORCID}

\section{Quan (iD https://orcid.org/0000-0003-1039-4819}

\section{References}

1. Grant J. Principles of curriculum design. In: Swanwick T, Forrest $\mathrm{K}, \mathrm{O}^{\prime}$ Brien $B C$ editors. Understanding medical education: evidence, theory, and practice. 3rd ed. Oxford: John Wiley \& Sons Ltd; 2019.

2. Christensen CM. The innovator's dilemma: when new technologies cause great firms to fail. Boston, Massachusetts: Harvard Business School Press; 1997.

3. Pouspourika K. The 4 Industrial Revolutions [Internet]. Institute of Entrepreneurship. 2019. (Accessed 19 Sep 2020). Available from: https://ied.eu/ project-updates/the-4-industrial-revolutions/.

4. Schwab K. The Fourth Industrial Revolution: what it means, how to respond [Internet]. World eEconomic Forum; 2016 Jan. (Accessed 19 Sep 2020). Available from: https://www.weforum.org/agenda/2016/01/ the-fourth-industrial-revolution-what-it-means-and-how-to-respond/\#.

5. Goy A, Nishtar S, Dzau V, et al. Health and healthcare in the Fourth Industrial Revolution. [Internet]. Global Future Council on the Future of Health and Healthcare 2016-2018. World Economic Forum; 2019 Apr. Available from: http://www3.weforum.org/docs/WEF__Shaping_the_Future_of_Health_ Council_Report.pdf.

6. Hamilton J. Outcomes in medical education must be wide, long and deep. Med Teach. 1999;21(2):125-6. https://doi.org/10.1080/01421599979725.

7. Guidance on the use of ultrasound locating devices for placing central venous catheters [Internet]. National Institute for Health and Care Excellence; 2002 Oct. (Accessed 20 Sep 2020). Available from: https://www.nice.org.uk/guidance/ta49/ chapter/1-Guidance.

8. Barrington MJ, Kluger R. Ultrasound guidance reduces the risk of local anesthetic systemic toxicity following peripheral nerve blockade. Reg Anesth Pain Med. 2013;38:289-99. https://doi.org/10.1097/AAP.0b013e318292669b.

9. Knowles M. Andragogy in action: applying modern principles of adult learning. San Francisco: Jossey-Bass; 1984.

10. Taylor $D$, Hamdy H. Adult learning theories: implications for learning and teaching in medical education: AMEE Guide No. 83. Med Teach. 2013;35(11):e1561-72. https://doi.org/10.3109/0142159X.2013.828153.

11. Egan $T$, Jaye C. Communities of clinical practice: the social organization of clinical learning. Health. 2009;13(1):107-25. https://doi.org/10.1177 $\% 2 F 1363459308097363$.

12. Lave J, Wenger E. Situated learning: Legitimate peripheral participants. New York: Cambridge University Press; 1991. https://doi.org/10.1017/CBO9780511815355.

13. FitzPatrick M, Clough J, Harvey P, Ratcliffe E. How can gastroenterology training thrive in a post-COVID world? Br Med J. 2020. Epub ahead of print. https://doi. org/10.1136/flgastro-2020-101601.

14. Hrastinski S. What do we mean by blended learning? TechTrends. 2019;63:564-9. https://doi.org/10.1007/s11528-019-00375-5.

15. Sandars J, Cleary T. Self-regulation theory: applications to medical education: AMEE Guide No. 58. Med Teach. 2011;33(11):875-86. https://doi.org/10.3109/01 42159X.2011.595434.

16. George A, Blaauw D, Green-Thompson L, et al. Comparison of video demonstrations and bedside tutorials for teaching paediatric clinical skills to large groups of medical students in resource-constrained settings. Int J Educ Technol High Educ. 2019;16:34. https://doi.org/10.1186/s41239-019-0164-z.

17. Hing YS, Chen PP, Wong GKC, Chan TTN. Simulation in medical education. J R Coll Physicians Edinb. 2019;49:52-7. https://doi.org/10.4997/JRCPE.2019.112.

18. Jackson K, Holton R, Hart-Hester S, Rudman W. Micro-credentials and the shifting healthcare ecosystem. J Interprofessional Workforce Res Dev. 2019;2.

19. Inequality Trends in South Africa. A multidimensional diagnostic of inequality [Internet]. Statistics South Africa; 2019. (Accessed 4 Sep 2020). Report No.: 03-10-19. Available from: www.statssa.gov.za/publications/Report-03-10-19217.

20. 30 human resources for health strategy: investing in the health workforce for universal health coverage. Pretoria: National Department of Health; 2020 Mar.

21. Frenk J, Chen L, Bhutta $Z$, et al. Health professionals for a new century: transforming education to strengthen health systems in an interdependent world. Lancet. 2010;376:1923-58. https://doi.org/10.1016/ S0140-6736(10)61854-5. 